\title{
Review
}

\section{Repurposing Licensed Drugs for Use Against Alzheimer's Disease}

\author{
Leslie C. Norins* \\ Alzheimer's Germ Quest, Naples, FL, USA
}

Pre-press 5 April 2021

\begin{abstract}
Substantial evidence, composed of drug mechanisms of action, in vivo testing, and epidemiological data, exists to support clinical testing of FDA-approved drugs for repurposing to the treatment of Alzheimer's disease (AD). Licensed compound investigation can often proceed at a faster and more cost-effective manner than un-approved compounds moving through the drug pipeline. As the prevalence of $\mathrm{AD}$ increases with life expectancy, the current rise in life expectancy amalgamated with the lack of an effective drug for the treatment of AD unnecessarily burdens our medical system and is an urgent public health concern. The unfounded reluctance to examine repurposing existing drugs for possible AD therapy further impedes the possibility of improving the quality of patient lives with a terminal disease. This review summarizes some evidence which exists to suggest certain already-approved drugs may be considered for the treatment of $\mathrm{AD}$ and will perhaps encourage physicians to off-label prescribe these safe therapeutics.
\end{abstract}

Keywords: Alzheimer's disease, amyloid- $\beta$, amyloid- $\beta$ protein precursor, cognitive dysfunction

\section{INTRODUCTION}

Many therapeutic areas including cancer, erectile dysfunction, irritable bowel syndrome, and attention deficit disorder have benefited from repositioning existing drugs. The established safety and tolerability of approved therapeutics considered for repurposing can lower the burdensome financial thresholds associated with in vitro and in vivo screening, dose optimization, toxicology, formulation, and manufacturing development. Commencing clinical trials to establish a drug's efficacy for the treatment of another disease is thus more accessible for pharmaceutical companies [1].

Although the underlying neurobiology and biochemistry of the orchestrated signaling cascades that definitively lead to the development of Alzheimer's disease (AD) is still under study and a subject of

\footnotetext{
${ }^{*}$ Correspondence to: Dr. Leslie Norins, 4301 Gulfshore Blvd., Suite 1404, Naples, FL 34103, USA. Tel.: +1239 649 1346; Email: leslie.norins@ALZgerm.org.
}

scientific debate, a more immediate course of action that may provide symptomatic treatment and perhaps even disease-modifying therapies for $A D$, is the repurposing of FDA-approved substances [2]. These drugs may prove to function more effectively than the existing pharmacotherapies indicated for the treatment of $\mathrm{AD}$, most of which only provide symptomatic relief for a six-month period [3]. Many of the drugs proposed here for repurposing possess a robust breadth of evidence for their effectiveness, while others require further investigation and further validation in standardized trials.

To facilitate the selection of approved drugs for further characterization against $\mathrm{AD}$, this review summarizes some of the existing preclinical, epidemiological, and clinical evidence for top drug candidates, presents evidence against further pursuing the repurposing of some previously suggested drugs, and highlights other drugs which may be useful to assess in future randomized clinical trials. While acknowledging that there is currently no known animal model which exactly recapitulates human $\mathrm{AD}$, and that 
often, this preclinical evidence does not translate to the bedside, this review delves into some of the in vitro and in vivo data that exist to support certain therapeutic candidates on the basis of improving ADassociated pathologies, functional disturbances and biomarkers, such as neuronal cell death, neuronal plasticity, $A \beta$ deposition, and tau protein hyperphosphorylation. The therapies reviewed here represent a sample of convenience as they are the most prevalent therapeutics in the literature and have also been cited in several systematic reviews. Some of the reviewed therapeutics may have the potential to not only provide symptomatic relief, but perhaps even modify the disease state, in turn easing some of the social and economic burdens associated with $\mathrm{AD}$.

Summarized evidence is presented for FDA-approved substances, with the potential to treat $A D$, including calcium channel blockers, phosphodiesterase inhibitors, insulin and glucagon-like peptide-1 (GLP1) receptor agonists, non-steroidal anti-inflammatory drugs, antibiotics, stimulants, mood stabilizers, antivirals, and antioxidants. The span of pharmacological categories covered serves to highlight the multifarious effects of $\mathrm{AD}$ and suggests that one pharmacotherapy may be insufficient to combat this baffling disease.

\section{CALCIUM CHANNEL BLOCKERS}

\section{Dihydropyridines}

Although a correlation exists between hypertension and $\mathrm{AD}$, hypertension often occurs along other vascular risk factors that have also been implicated in the progression of $\mathrm{AD}$ [4]. Calcium channel blockers (CCBs) provide vasodilatory effects on smooth muscle vasculature accounting for their benefit as antihypertensives. Easily crossing the blood-brain barrier to also increase blood flow to the brain, CCBs have also been suspected to grant neuroprotection as some evidence exists to indicate their potential to reduce the incidence of AD. Dihydropyridines such as nimodipine (FDA-approved for reducing the severity of ischemia), nivaldipine, and nitrendipine are some of the most widely available calcium channel blockers.

In vitro studies of CCBs have demonstrated their effectiveness in improving cell survival in presence of $A \beta$, rescuing $A \beta$-induced neurotoxicity, and decreasing overall $A \beta$ production and oligomeric accumulation [5-7]. Other in vitro studies have indicated the protective effects of nimodipine in $\mathrm{A} \beta$-induced cytotoxicity. Nimodipine reduced secretion of $A \beta$ in other cell types of the brain such as in microglia [8].

In vivo studies further substantiate the use of dihydropyridine CCBs as treatment for AD. Not only have some in vivo studies on dihydropyridines such as nivaldipine significantly increased $A \beta$ clearance in transgenic mouse models of $\mathrm{AD}, \mathrm{Tg}$ APPsw (Tg2576) and Tg PS1/APPsw, but have also reversed memory and learning deficits measured through behavioral testing using the Morris Water Maze [9]. Indeed, other studies demonstrated the neuroprotective effects of nilvadipine, which prevented impairment of spatial memory and apoptosis in the hippocampus in rats stereotactically injected with $\mathrm{A} \beta$ - the circuit of the brain primarily responsible for learning by encoding declarative and spatial memories [10]. Likewise, nimodipine mitigated prevalent pathologies associated with $\mathrm{AD}$, such as apoptosis and pathological lesions in neurons of the hippocampus and cortex and inhibited tau hyperphosphorylation in rats with chronic cerebral hyperfusion $(\mathrm{CCH})$ which promotes hyperphosphorylation of tau proteins [11]. These studies also indicated that nimodipine rescued spatial memory deficits induced by $\mathrm{CCH}$.

Although substantial preclinical evidence exists to suggest that some dihydropyridines could treat $\mathrm{AD}$ in patients, the NILVAD study, involving participants over the age of 50 meeting NINCDS-ADRDA standards for diagnosis of probable $\mathrm{AD}$, failed to show any cognitive benefit of treatment with nilvadipine [12]. However, the neuroprotective effects of nilvadipine on patients without diagnosed $A D$ have not been tested. It is conceivable that a drug may only work in earlier disease phases but may fail to act once the disease is more progressed. Indeed, this study showed that patients at an earlier stage of AD in the experimental group performed better in memory and language measurements than the placebo group, with a $\sim 50 \%$ decrease in cognitive decline. Further clinical studies are required to test the neuroprotective effects of nilvadipine on patients with a predisposition to $\mathrm{AD}$ without any clinical presentations of the disease. However, although nilvadipine is approved for use in Europe and Japan, it is not FDA-approved. Efforts should focus on other dihydropyridines that have gone through the rigorous approval process in the United States.

The similar chemical structure and proposed mechanisms of action of nimodipine to that of nilvadipine would suggest that nimodipine could also have no clinical benefits for patients with AD. A systematic 
review analyzed the efficacy of nimodipine on symptoms of dementia in individuals with $\mathrm{AD}$, cerebrovascular disease, mixed $\mathrm{AD}$, and cerebrovascular disease and in unclassified disease [13]. It encompassed 14 randomized clinical trials and surprisingly found an improvement in SCAG scale and cognitive function associated with the use of this drug. Although clinical trials have reported the efficacy of nimodipine in improving cognition, they were small, short, and did not directly measure treatment's effect on progressive AD pathology. These limited, yet promising, clinical studies, as well as longitudinal epidemiological evidence suggesting the potential neuroprotective effects of dihydropyridine CCBs, can serve as preliminary rationale for a more robust clinical trial studying the effects of already-approved nimodipine on $\mathrm{AD}$ [14]. Unfortunately, there are currently no registered clinical trials on ClinicalTrials.gov nor the International Standard Randomized Controlled Trial Number (ISRCTN) databases.

\section{Dantrolene}

Dantrolene is indicated for treatment of muscle spasticity. It is a CCB as it antagonizes ryanodine receptors (RyRs), thus inhibiting the release of $\mathrm{Ca}^{2+}$ from endoplasmic reticulum (ER) stores. RyRs are increased in $\mathrm{AD}$ in the hippocampus, and excess $\mathrm{Ca}^{2+}$ release from ER can lead to mitochondrial free radical release resulting in oxidative stress and neuronal cell death $[15,16]$. Thus, it seems logical to consider dantrolene for the treatment of AD.

In vitro dantrolene increased the presence of antiapoptotic protein $\mathrm{Bcl} 2$ and decreased neuronal cell death [17]. Subsequent in vivo evidence from multiple studies implicates it as a potential therapeutic for $A D$. It reduced $A \beta$ load in the hippocampus and memory deficits in both a $\operatorname{Tg} 2576$ and a triple transgenic AD mouse model ( $3 \times \mathrm{Tg}-\mathrm{AD})$, normalized $\mathrm{ER} \mathrm{Ca}^{2+}$ signaling and restored synaptic transmission and neuroplasticity (the molecular correlate of learning and memory) in 3xTg-AD mice [18-20]. As promising as these results are, no current registered clinical trial exists to test the effects of dantrolene on AD.

\section{PHOSPHODIESTERASE (PDE) INHIBITORS}

\section{Sildenafil}

Sildenafil, more commonly known by its brand name as Viagra, functions as a phosphodiesterase type 5 (PDE5) inhibitor and is used to treat erectile dysfunction and pulmonary hypertension. PDE5 protein is significantly upregulated in the temporal cortex of patients with AD [21]. Cyclic guanosine monophosphate (cGMP), degraded by PDE5, is present at lower concentrations in the cerebrospinal fluid (CFS) of patients with AD. Typically, cGMP upregulates expression of proliferator-activated receptor- $\gamma$ coactivator $1 \alpha(\mathrm{PGC} 1 \alpha)$ - thought to indirectly suppress $A \beta$ generation $[22,23]$. Thus, PDE5 has been proposed as a therapeutic target for AD.

In vitro sildenafil prevented the $\mathrm{A} \beta$-induced oxidative stress and cell death [24]. Another study corroborated these findings by demonstrating decreased caspase activation and apoptosis after treatment with sildenafil in hippocampal cells [25]. In vivo studies demonstrated a memory improvement in rats with a concomitant increase in hippocampal cGMP levels after phosphodiesterase inhibitor administration [26]. Regular treatment with sildenafil also increased cognitive function and $\mathrm{A} \beta$ load in APP/PS1 AD mouse models, and mitigated tau pathology in the hippocampus of a senescence-accelerated mouse model (SAMP8) while ameliorating cognitive impairments $[27,28]$.

A link between cerebrovascular disease and AD pathology has been proposed [29]. Thus, improved cardiovascular function is a coveted goal for intervening with $\mathrm{AD}$ progression. To this end, a clinical study demonstrated the increase in cerebral oxygen after sildenafil administration in patients with $\mathrm{AD}$ [30]. Interestingly, a more recent pilot study revealed that sildenafil normalized fractional amplitude of low frequency fluctuations (fALff) in hippocampus (increased fALff has been revealed in AD) [31]. These and other results may be used as preliminary evidence to justify more clinical trials of this molecule against $\mathrm{AD}$.

\section{INSULIN AND GLUCAGON-LIKE PEPTIDE-1 (GLP-1) RECEPTOR AGONISTS}

\section{Nasal or infused insulin and liraglutide}

Type 2 diabetes has been identified as a risk factor for $\mathrm{AD}$ due to the substantial overlap in comorbidities and potential pathomechanisms leading to each disease. It is characterized by impaired insulin signaling-imperative for glucose metabolism. Likewise, aberrant brain insulin signaling has been 
extensively documented in $\mathrm{AD}[32,33]$. Other than its involvement in bioenergetics and metabolism, the biochemical pathways which insulin regulates in the brain are still under study and are likely numerous. However, sizable evidence suggests a role for cerebral insulin in synaptic spine formation and viability, neurotransmitter turnover, inflammation, vasodilation, and more prominently the turnover of $A \beta$ and tau phosphorylation [34]. Moreover, expression of glucose transporters at the blood-brain barrier is decreased even before the onset of AD pathological symptoms [35]. The putative multifarious pathways involving cerebral insulin suggest how dysregulation of insulin could be detrimental and potentially result in neurodegeneration. These rationales have led to studies of cerebral insulin and GLP-1 analogues as plausible treatments for $\mathrm{AD}$ [36].

GLP-1 analogues mimic glucagon-like peptide 1 which is a hormone that promotes the secretion of insulin, in turn lowering blood sugar. The well-established blood-brain barrier permeability of GLP-1 analogues such as liraglutide, make them great candidates for directly modifying neurobiology even when peripherally injected [37]. The FDA has approved Saxenda, Victoza (liraglutide), and Byetta (excendin4) for use in the United States. These are liraglutide injectables indicated as adjuncts to exercise to promote glycemic control in individuals with Type 2 diabetes.

GLP-1 analogues in vitro demonstrated reduced cell death, $A \beta P P$ and $A \beta$ levels through mechanisms associated with glycogen synthase kinase $3 \beta$ (GSK3 $\beta$ ) and decreased tau phosphorylation $[38,39]$. Similarly, insulin reduced intraneuronal A $\beta$ [40].

In vivo mouse models have been used to demonstrate the neuroprotective effects of these analogues. Although Val(8)GLP-1 is a GLP-1 analogue specific for mice, it is important to point out that in APP/PS1 mice, Val(8)GLP-1 decreased load of $A \beta$ plaques and protected synaptic plasticity [41]. Similarly, neuroplasticity was protected in type 2 diabetes mouse models (high-fat-diet-fed mice) injected with human GLP-1 analogue excendin-4 [42]. These mice also exhibited an increase in recognition index, indicating improve learning and memory.

The rate of neurogenesis, which normally occurs in brain regions such as the dentate gyrus (DG) of the hippocampus, is decreased as a result of AD. Another study in type 2 diabetes mouse models (leptin-deficient ob/ob, db/db, and high-fat-diet-fed mice) interestingly found neuronal progenitor cell proliferation in the DG of hippocampus in mice injected with liraglutide or excendin-4, suggesting an increase in neurogenesis [43]. Other in vivo studies in rats have also focused on the direct effects of insulin on inhibiting $A \beta$ oligomers and restoring $A \beta$-induced suppression of neuroplasticity [44].

Clinical trials of GLP-1 analogues have demonstrated that liraglutide increased the blood-brain glucose transfer capacity in the cerebral cortex of subjects with $\mathrm{AD}$ [45]. As a result, cognition positively correlated with glucose utilization in study subjects. This is of particular importance since bloodbrain transfer capacity diminishes with duration of AD. Currently there is another ongoing clinical trial studying liraglutide and its effects on AD [46]. The study is also looking at cerebral glucose metabolic rate, changes in cognitive and functional abilities and several other biomarkers; however, results are not yet available.

Aside from GLP-1 analogue administration, the direct delivery of insulin may have beneficial effects on patients with $\mathrm{AD}$. In a pilot clinical study, nasal delivery of insulin improved delayed memory associated with mild cognitive impairment (MCI) or $\mathrm{AD}$ and preserved general cognition and changes in the cerebral metabolic rate of glucose in bilateral occipital, right temporal, bilateral frontal, and right precuneus and/or cuneus regions [47]. In exploratory analysis, improved cognition, in participants on insulin with MCI or AD, was associated with an increase in CSF $A \beta_{42}$ levels and a decrease in tau protein $/ A \beta_{42}$ [47]. Another study involving intranasal insulin Detemir increased verbal working memory and visuospatial memory in adults with $\mathrm{AD}$ or MCI who were apolipoprotein E $\varepsilon 4$ (APOE $\varepsilon 4)$ carriers [48]. Likewise, another study demonstrated that insulin improved memory in individuals diagnosed with MCI or AD who were treated with insulin, reduced the tau-P181/A $\beta_{42}$ ratio and preserved or increased MRI volume in AD-associated brain regions (left cuneus, right middle cingulum, right parahippocampal gyrus, and left superior parietal cortex) [49]. Although the pre-clinical data, epidemiological studies, and some clinical data suggest a role for insulin in the treatment of $\mathrm{AD}$, other randomized clinical studies have not found significant improvements in patients with $\mathrm{AD}$ who were administered infused or nasal insulin [50-52]. More studies are needed to detangle the conflicting results of these different trials and determine the effects of insulin on individuals with less advanced forms of AD. Perhaps individual characteristics determine whether a person responds or not. 


\section{NON-STEROIDAL} ANTI-INFLAMMATORY DRUGS (NSAIDS)

\section{Diclofenac}

Increasing evidence suggests that inflammation is an early neuropathological event in $\mathrm{AD}$ [53, 54]. Diclofenac, like other NSAIDs, is currently approved for ameliorating pain and inflammation, and it is specifically indicated for reliving osteoarthritis and rheumatoid arthritis signs and symptoms. Preclinical research demonstrated that fenamate NSAIDs, chemically related to diclofenac, conferred neuroprotection in 3xTgAD mouse models [55].

Epidemiological evidence suggests a role for NSA IDs in reducing the risk of AD [56]. Specifically, a study analyzing the Alzheimer's Disease Neuroimaging Initiative (ADNI) database used logistic regression and modeling to tease out prevalence of $\mathrm{AD}$ and cognitive decline for individuals taking commonly used NSAIDs. Paralleling animal studies, diclofenac use was negatively correlated with cognitive decline and AD incidence [57]. No other investigated NSAIDs had significant associations with cognitive abilities. Additionally, one recent observational cohort study found that $\mathrm{AD}$ frequency was significantly decreased in the diclofenac group compared to other NSAID groups [54]. This small, but promising result further bolsters the need for investigating the pharmacological interactions diclofenac participates in as regards AD.

\section{STIMULANTS}

\section{Modafinil}

Modafinil is a stimulant, pharmacologically distinct from other well-known ones, used to treat symptoms of excessive sleepiness caused by obstructive sleep apnea or narcolepsy [58]. It is thought to enhance cognitive performance-the most prevalent loss resulting from a neurodegenerative disease such as AD [59]. Additionally, modafinil improved hippocampal neurogenesis, global mental status, and attention [58].

Preclinical studies in both mice and rats show that not only does short-term treatment with modafinil promote DG hippocampal neurogenesis and decrease cell death, but also normalizes brain-derived neurotrophic factor (BDNF) expression, which is known to be deficient in individuals with $\mathrm{AD}[60,61]$. Other rat studies further demonstrated the behavioral benefits of modafinil on working memory as administration of it increased performance in the Morris Water Maze [62]. These studies did not test the effects of modafinil on AD animal models, which may explain why clinical studies have not been pursued more vigorously.

Clinical evidence for one study concluded that the administration of modafinil did not change apathy in individuals with $\mathrm{AD}$ [63]. However, no other ADrelated symptomology was directly tested.

No registrations of clinical trials testing the effect of modafinil on $\mathrm{AD}$ currently exist.

\section{MOOD STABILIZERS}

\section{Lithium}

Even with well-established safety and tolerance data, and decades of use in the United States, a comprehensive list of lithium's pharmacological mechanisms have yet to be composed. However, even though lithium is currently indicated for the treatment of acute manic episodes, the element has been proposed to cover at least 16 biochemical pathways which become aberrant in $\mathrm{AD}$ [16]. The putative neuroprotective effects of lithium are thus too numerous to mention but include the regulation of oxidative stress, autophagy, mitochondrial dysfunction and inflammation (extensively reviewed in [16]).

Lithium significantly reduces tau phosphorylation and $A \beta$ production by modulating $A \beta P P$ processing in in vivo studies of AD mouse models (FTDP-17 tau and GSK-3 $\beta$ overexpressing mice) [64]. Likewise, micro-dosed lithium restored memory loss and hippocampal neurogenesis in AD-like amyloid pathology rats (McGill-R-Thy-APP transgenic rats) [65]. These same rats had reduced amyloid levels in the hippocampus. The attenuation of tau and $A \beta$ pathology and the increased cognitive function shown in rodent models has given way to probing the effects of lithium on $\mathrm{AD}$ in humans.

Epidemiological data show a negative correlation between the prevalence of dementia and the lithium content in drinking water, suggesting that long-term exposure to lithium, even at microlevels, may prevent or reduce the severity of $\mathrm{AD}$ [66]. Indeed, a short clinical study reported the restoration of BDNF serum levels and increased cognitive improvement in patients with early AD [67]. Another clinical study reported increased memory and attention and decreased tau phosphorylation in the CSF of subjects taking lithium [68]. The continuation of this study 
concluded that lithium-treated subjects maintained cognitive stability for over two years after treatment [69]. It demonstrated an increase in A $\beta$ in CFS of individuals, suggesting disease-modifying properties of lithium. The multitude of AD-associated pathways targeted by lithium indicate testing it for $\mathrm{AD}$ should be given high priority.

\section{ANTIVIRALS}

Acyclovir

Acyclovir is a nucleoside analog that acts as an antiviral compound used against herpes virus. Herpes is known to cause brain damage in several regions [70]. Given its direct impact on the brain, some in the scientific community postulate that herpes simplex virus 1 (HSV1) leads to the development of $\mathrm{AD}$ in $A P O E \& 4$ carriers by generating $\mathrm{A} \beta$, precipitating hyperphosphorylation of tau and disrupting autophagy [71]. Plasma from 360 individuals was analyzed to reveal that heterozygous APOE $\varepsilon 4$ subjects with antibodies for HSV1 had an increased risk for developing $\mathrm{AD}$ [72]. Other studies in postmortem tissue, showing the colocalization of HSV1 DNA to $\mathrm{A} \beta$ plaques, concur that HSV1 may be an etiological factor in $\mathrm{AD}$ [73].

A recent population-based cohort study concluded that anti-herpetic medication correlated with a decreased risk of developing dementia [74]. Although retrospective in nature and compiling data from patients taking other antivirals, the study also included data of patients taking acyclovir. Further evidence is needed to highlight causal effects of microbes on $\mathrm{AD}$ [75]. Additionally, more robust clinical trials on $A P O E \& 4$ carriers are needed to determine whether acyclovir, among other antivirals, is effective in preventing the onset of $\mathrm{AD}$.

\section{ANTIBIOTICS}

\section{Minocycline}

Out of the many tetracycline antibiotics, minocycline is the most effective in crossing the blood-brain barrier. It is an anti-inflammatory drug with a broad spectrum of activity that serves as an antibiotic. Its antioxidant activity has also been shown to attenuate oxidative-stress induced neurotoxicity [76]. Minocycline also combats the effects of $A \beta$ in pre-clinical studies and is known to address at least four known pathways which are aberrant in AD [16].
Minocycline stabilizes mitochondria and inhibits JNK activation [77]. JNK2 and JNK3 activation has been associated with plaques and neurofibrillary tangles [78]. A $\beta$-induced cytotoxicity and cleavage of $\mathrm{A} \beta \mathrm{PP}$ was decreased by the inhibition of JNK, which led to a decrease of soluble $A \beta$ oligomers [79]. In vitro evidence has demonstrated that minocycline not only inhibits aggregate formation of $\mathrm{A} \beta$, but also destroys fibrils [80].

In vivo studies in high-fat-diet rats and $3 \mathrm{xTg}-\mathrm{AD}$ mouse models reporting decreases in $A \beta$ accumulation with concomitant behavioral improvements further position minocycline as a candidate for clinical trials $[81,82]$. These reports included increased performance on spatial learning tasks and restored cortex-, hippocampus-, and amygdala-dependent learning and memory. Further preclinical studies in TG-SwDI transgenic mice demonstrated a reduction of pro-inflammatory markers after minocycline administration [83].

The promising in vivo results do not seem translatable. A clinical study found that patients with $\mathrm{AD}$ taking minocycline had no significant improvement compared to control subjects in Mini-Mental State Examination scores nor in Bristol Activities of Daily Living Scale scores [84]. However, these data are derived from a limited study where no biomarkers were used to confirm the patient's AD diagnosis. The statistical power of the study also decreased when many participants dropped out of the study due to gastrointestinal and dermatological side-effects from the antibiotic. Further testing of cognitive and functional abilities and AD biomarker measurements is required to determine if minocycline is effective in treating AD. However, the feasibility of future studies is bleak given the high-dose requirements $(400 \mathrm{mg})$ of the putative treatment.

\section{Rifamycin}

Commonly used for the treatment of tuberculosis, rifamycin is another powerful antibiotic that has been suggested for the treatment of AD. In vitro, it reduced $\mathrm{A} \beta$ production while increasing $\mathrm{A} \beta$ clearance [85]. Further evidence exists to suggest rifamycin's antiamyloid, anti-inflammatory, anti-tau, and cholinergic effects [86].

Although preclinical in vitro studies suggest neuroprotective activity of rifamycin and even demonstrate pro-cognitive effects, limited clinical findings exist regarding the efficacy of this drug on $\mathrm{AD}$ [86]. However, rifampin, a semi-synthetic derivative of 
rifamycin, was used in conjunction with doxycycline to investigate their therapeutic role in the treatment of AD [87]. The antibiotic- treated groups experienced significantly less decline in the standardized Alzheimer's Disease Assessment Scale cognitive subscale score. However, a more recent study reported contradictory findings by concluding that there was no significant benefit in cognition or function in $\mathrm{AD}$ patients receiving a dose of doxycycline and rifampin in combination or individually [88].

\section{ANTIOXIDANTS}

\section{Melatonin}

Aside from some of the above-mentioned substances which have antioxidant properties, but fit more cleanly into other pharmacological categories, melatonin is a powerful antioxidant [89]. It decreases with age, exposing the cells to increased oxidative stress, putatively contributing to neurodegenerative cascades which lead to AD. The increase in reactive oxygen species derived from aging could benefit from exogenous melatonin which may curb the associated increase in oxidized proteins and damaged DNA by scavenging free radicals. Melatonin is also believed to target inflammatory pathways associated with neurodegeneration.

It has been understood for over a decade that melatonin can prevent the formation of amyloid fibrils [90]. In vitro melatonin decreases secretion of soluble $A \beta$ in different cell types and decreased the prevalence of proinflammatory cytokines such as IL6 [91, 92]. Given its pleiotropic essence, melatonin also protects cells form apoptosis and oxidative damage conferred by $\mathrm{A} \beta$-induction and attenuates tau hyperphosphorylation [93-95].

In vivo studies of $\mathrm{Tg} 2576$ transgenic mice revealed that melatonin further increased survival and inhibited oxidative pathology and amyloid deposition in brain regions such as cortex and [96, 97]. Additionally, melatonin mollified memory impairment, neuroinflammation, and neurodegeneration in an aging mouse model [98]. These and other studies in rats injected with fibrillary $A \beta$ revealed reduced level of reactive oxygen species and pro-inflammatory mediators [99]. In addition, melatonin decreased tau hyperphosphorylation, enhanced memory function and reduced oxidative stress in melatonin-biosynthesis-inhibited rats [100]. Interestingly, melatonin was more effective in mice before the first signs of hippocampal and cortical plaques compared to older mice that had already developed plaque deposition, an informative finding to guide recruitment for future clinical studies $[96,101]$.

Given these promising preclinical results, data on how melatonin impacts human subjects with dementia have been collected for several decades. It improved memory retention in older individuals [102]. In subjects with moderate to advanced dementia, sundowning was ameliorated by the use of melatonin [103]. Longer and more recent studies further shed light on its benefits to subjects with MCI, as these patients improved in cognitive examinations such as the Mattis' test, Digit-symbol test, Trail A and B tasks, the Rey's verbal test, MiniMental State Examination, and the AD Assessment Scale $[104,105]$. Keeping in mind that these studies did not report any biomarker data associated with ameliorating disease but, given that melatonin is an over-the- counter medication, relatively inexpensive, and is also endogenously produced, patients with $\mathrm{AD}$ and $A P O E \& 4$ carriers could consider this substance as a low-risk potential co-treatment strategy.

\section{CONCLUSION}

The heavy burden AD presents on our medical system is only increasing as life expectancy grows and the world's population exponentially multiplies. Decreasing the severity or even onset of $A D$ in the population, especially in predisposed individuals, by finding disease-modifying therapies might be achieved more quickly by repurposing medications for which clinical safety and tolerance has been well established. With potentially high benefit-risk ratios, re-establishing clinical trials for the purpose of studying the effects of approved drugs on $\mathrm{AD}$ can be the path of least resistance in the drug development pipeline.

This review has identified FDA-approved therapeutics, commonly cited in literature and systematic reviews, for repurposing as some evidence exists to suggest that they may be useful in the treatment of AD. Although this review focused on therapeutics commonly proposed in the literature, including systematic reviews, we did not perform a systematic review of our own and acknowledge that articles cited here represent a sample of convenience. Despite this limitation, which inevitably reduces the strength of our conclusion, we identified gaps of knowledge on this topic. Particularly we identified a lack of ongoing 
clinical trials to investigate repurposing existing therapeutics. We have also reviewed some issues with current evidence not translating from animal models to a clinical setting, and possible intolerability to patients of drugs like minocycline which are required at too high a dose. Further assessment of epidemiological data could help guide researchers in the choice of single or combination therapies to test in clinical trials. However, the most robust data to begin evidence-based clinical trials for priority candidate drugs as a treatment for AD may come from the combined efforts of preclinical research, epidemiological data, and in depth in silico transcriptional analyses, such as connectivity map (CMAP) project and platform-independent expression database (SPIED) [106]. The resulting top candidates have the potential to change the current, merely palliative, AD treatments into more proactive approaches.

Given the multitude of signaling pathways whose aberrant function is known to contribute to $\mathrm{AD}$, there may not be a single drug that proves to be the panacea. A combination therapy addressing at least several, non-overlapping biochemical pathways of the 25 currently identified pathways may be the answer to treating and even modifying an AD state [16]. Fortuitously, some of the drugs described in this review, such as lithium, cover multiple pathways.

A combinatorial drug approach adds to the complexity of establishing clinical trials where multiple drugs are administered with no serious drug-drug interactions. Although establishing the safety of a combinatorial drug treatment sums another hurdle to establishing efficacy in the developmental pipeline, if we truly desire to curb the medical burden of this elusive disease, we must act promptly to enact clinical trials which address several questions. First, can a single drug or combination treatment prevent disease progression in patients with mild to moderate AD? Second, can a single drug or combination treatment reverse disease progression in patients with mild to advanced AD? Third, can a single drug or combination treatment prevent disease onset in individuals at increased risk of developing $\mathrm{AD}$ ( $A P O E \varepsilon 4$ carriers)?

This third question arises from lessons that must be learned from failed trials and points that must be taken into consideration before proceeding with further clinical trials to repurpose drugs for AD treatment. First, the recruitment of elderly participants may confound the results of clinical trials as these participants suffer from comorbidities and other pathologies which make studying an already enigmatic-disease even more perplexing [107]. Second, some postulate the reason numerous clinical trials for AD therapies did not come to fruition was because the trials targeted a disease state that had already progressed beyond putative treatment or reversal. Although this is still an uncertain subject, it may be beneficial to identify the AD-prone population, such as $A P O E$ \& 4 carriers, and commence AD treatment at initial stages of the disease, or even before any symptoms arise. Early detection is imperative since the degenerative process can commence 20-30 years before AD symptoms, during which time $A \beta$ plaque deposition and neurofibrillary tangle amount [108].

Finally, because research exists in the real world and not an ivory tower, we must be cognizant of economic realities. The pharmaceutical industry is understandably loath to invest further hundreds of millions of dollars in field trials of compounds which cannot be patented and are generic. Thus, the two potential funders for such costly investigations are private foundations and the Unites States government. But how many researchers have proposed pertinent clinical trials to either?

\section{DISCLOSURE STATEMENT}

The author's disclosure is available online (https:// www.j-alz.com/manuscript-disclosures/21-0080r2).

\section{REFERENCES}

[1] Corbett A, Pickett J, Burns A, Corcoran J, Dunnett SB, Edison P, Hagan JJ, Holmes C, Jones E, Katona C, Kearns I, Kehoe P, Mudher A, Passmore A, Shepherd N, Walsh F, Ballard C (2012) Drug repositioning for Alzheimer's disease. Nat Rev Drug Discov 11, 833-846.

[2] Karran E, Mercken M, Strooper BD (2011) The amyloid cascade hypothesis for Alzheimer's disease: An appraisal for the development of therapeutics. Nat Rev Drug Discov 10, 698-712.

[3] Ballard C, Corbett A, Sharp S (2011) Aligning the evidence with practice: NICE guidelines for drug treatment of Alzheimer's disease. Expert Rev Neurother 11, 327-329.

[4] Posner HB, Tang M-X, Luchsinger J, Lantigua R, Stern Y, Mayeux R (2002) The relationship of hypertension in the elderly to AD, vascular dementia, and cognitive function. Neurology 58, 1175-1181.

[5] Zhao W, Wang J, Ho L, Ono K, Teplow DB, Pasinetti GM (2009) Identification of antihypertensive drugs which inhibit amyloid-beta protein oligomerization. J Alzheimers Dis 16, 49-57.

[6] Bachmeier C, Beaulieu-Abdelahad D, Mullan M, Paris D (2011) Selective dihydropyiridine compounds facilitate the clearance of $\beta$-amyloid across the blood-brain barrier. Eur J Pharmacol 659, 124-129.

[7] Anekonda TS, Quinn JF, Harris C, Frahler K, Wadsworth TL, Woltjer RL (2011) L-type voltage-gated calcium channel blockade with isradipine as a therapeutic strategy for Alzheimer's disease. Neurobiol Dis 41, 62-70. 
[8] Sanz JM, Chiozzi P, Colaianna M, Zotti M, Ferrari D, Trabace L, Zuliani G, Di Virgilio F (2012) Nimodipine inhibits IL-1 $\beta$ release stimulated by amyloid $\beta$ from microglia. Br J Pharmacol 167, 1702-1711.

[9] Paris D, Bachmeier C, Patel N, Quadros A, Volmar C-H, Laporte V, Ganey J, Beaulieu-Abdelahad D, Ait-Ghezala G, Crawford F, Mullan MJ (2011) Selective antihypertensive dihydropyridines lower $A \beta$ accumulation by targeting both the production and the clearance of $\mathrm{A} \beta$ across the blood-brain barrier. Mol Med 17, 149-162.

[10] Iwasaki K, Egashira N, Takagaki Y, Yoshimitsu Y, HatipAl-Khatib I, Mishima K, Fujiwara M (2007) Nilvadipine prevents the impairment of spatial memory induced by cerebral ischemia combined with beta-amyloid in rats. Biol Pharm Bull 30, 698-701.

[11] Tan Z, Chen Y, Xie W, Liu X, Zhu Y, Zhu Y (2018) Nimodipine attenuates tau phosphorylation at Ser396 via miR-132/GSK-3 $\beta$ pathway in chronic cerebral hypoperfusion rats. Eur J Pharmacol 819, 1-8.

[12] Lawlor B, Segurado R, Kennelly S, Olde Rikkert MGM, Howard R, Pasquier F, Börjesson-Hanson A, Tsolaki M, Lucca U, Molloy DW, Coen R, Riepe MW, Kálmán J, Kenny RA, Cregg F, O’Dwyer S, Walsh C, Adams J, Banzi R, Breuilh L, Daly L, Hendrix S, Aisen P, Gaynor S, Sheikhi A, Taekema DG, Verhey FR, Nemni R, Nobili F, Franceschi M, Frisoni G, Zanetti O, Konsta A, Anastasios O, Nenopoulou S, Tsolaki-Tagaraki F, Pakaski M, Dereeper O, de la Sayette V, Sénéchal O, Lavenu I, Devendeville A, Calais G, Crawford F, Mullan M, NILVAD Study Group (2018) Nilvadipine in mild to moderate Alzheimer disease: A randomised controlled trial. PLoS Med 15, e1002660.

[13] Birks J, López-Arrieta J (2002) Nimodipine for primary degenerative, mixed and vascular dementia. Cochrane Database Syst Rev, CD000147

[14] Kennelly S, Abdullah L, Kenny RA, Mathura V, Luis CA, Mouzon B, Crawford F, Mullan M, Lawlor B (2012) Apolipoprotein E genotype-specific short-term cognitive benefits of treatment with the antihypertensive nilvadipine in Alzheimer's patients-an open-label trial. Int J Geriatr Psychiatry 27, 415-422.

[15] Kelliher M, Fastbom J, Cowburn RF, Bonkale W, Ohm TG, Ravid R, Sorrentino V, O’Neill C (1999) Alterations in the ryanodine receptor calcium release channel correlate with Alzheimer's disease neurofibrillary and beta-amyloid pathologies. Neuroscience 92, 499-513.

[16] Fessel J (2019) Prevention of Alzheimer's disease by treating mild cognitive impairment with combinations chosen from eight available drugs. Alzheimers Dement $(N Y) \mathbf{5}$, 780-788.

[17] Wei H, Leeds P, Chen RW, Wei W, Leng Y, Bredesen DE, Chuang DM (2000) Neuronal apoptosis induced by pharmacological concentrations of 3-hydroxykynurenine: Characterization and protection by dantrolene and $\mathrm{Bcl}-2$ overexpression. J Neurochem 75, 81-90.

[18] Peng J, Liang G, Inan S, Wu Z, Joseph DJ, Meng Q, Peng Y, Eckenhoff MF, Wei H (2012) Dantrolene ameliorates cognitive decline and neuropathology in Alzheimer triple transgenic mice. Neurosci Lett 516, 274-279.

[19] Oulès B, Del Prete D, Greco B, Zhang X, Lauritzen I, Sevalle J, Moreno S, Paterlini-Bréchot P, Trebak M, Checler F, Benfenati F, Chami M (2012) Ryanodine receptor blockade reduces amyloid- $\beta$ load and memory impairments in Tg2576 mouse model of Alzheimer disease. J Neurosci 32, 11820-11834.
[20] Chakroborty S, Briggs C, Miller MB, Goussakov I, Schneider C, Kim J, Wicks J, Richardson JC, Conklin V, Cameransi BG, Stutzmann GE (2012) Stabilizing ER $\mathrm{Ca} 2+$ channel function as an early preventative strategy for Alzheimer's disease. PLoS One 7, e52056.

[21] Ugarte A, Gil-Bea F, García-Barroso C, Cedazo-Minguez Á, Ramírez MJ, Franco R, García-Osta A, Oyarzabal J, Cuadrado-Tejedor M (2015) Decreased levels of guanosine 3', 5'-monophosphate (cGMP) in cerebrospinal fluid (CSF) are associated with cognitive decline and amyloid pathology in Alzheimer's disease. Neuropathol Appl Neurobiol 41, 471-482.

[22] Kwak Y-D, Wang R, Li JJ, Zhang Y-W, Xu H, Liao FF (2011) Differential regulation of BACE1 expression by oxidative and nitrosative signals. Mol Neurodegener $\mathbf{6}, 17$.

[23] Sanders O (2020) Sildenafil for the treatment of Alzheimer's disease: A systematic review. J Alzheimers Dis Rep 4, 91-106.

[24] Son Y, Kim K, Cho H-R (2018) Sildenafil protects neuronal cells from mitochondrial toxicity induced by $\beta$ amyloid peptide via ATP-sensitive $K+$ channels. Biochem Biophys Res Commun 500, 504-510.

[25] Sung SK, Woo JS, Kim YH, Son DW, Lee SW, Song GS (2016) Sildenafil ameliorates advanced glycation end products-induced mitochondrial dysfunction in HT-22 hippocampal neuronal cells. J Korean Neurosurg Soc 59, 259-268.

[26] Prickaerts J, Steinbusch HWM, Smits JFM, de Vente J (1997) Possible role of nitric oxide-cyclic GMP pathway in object recognition memory: Effects of 7-nitroindazole and zaprinast. Eur J Pharmacol 337, 125-136.

[27] Puzzo D, Staniszewski A, Deng SX, Privitera L, Leznik E, Liu S, Zhang H, Feng Y, Palmeri A, Landry DW, Arancio O (2009) Phosphodiesterase 5 inhibition improves synaptic function, memory, and amyloid-beta load in an Alzheimer's disease mouse model. J Neurosci 29, 80758086.

[28] Orejana L, Barros-Miñones L, Jordán J, Puerta E, Aguirre N (2012) Sildenafil ameliorates cognitive deficits and tau pathology in a senescence-accelerated mouse model. $\mathrm{Neu}$ robiol Aging 33, 625.e11-625.e20.

[29] Zlokovic BV (2011) Neurovascular pathways to neurodegeneration in Alzheimer's disease and other disorders. Nat Rev Neurosci 12, 723-738.

[30] Sheng M, Lu H, Liu P, Li Y, Ravi H, Peng S-L, DiazArrastia R, Devous MD, Womack KB (2017) Sildenafil improves vascular and metabolic function in patients with Alzheimer's disease. J Alzheimers Dis 60, 1351-1364.

[31] Samudra N, Motes M, Lu H, Sheng M, Diaz-Arrastia R, Devous M, Hart J, Womack KB (2019) A pilot study of changes in medial temporal lobe fractional amplitude of low frequency fluctuations after sildenafil administration in patients with Alzheimer's disease. J Alzheimers Dis 70, 163-170.

[32] Moloney AM, Griffin RJ, Timmons S, O'Connor R, Ravid R, O'Neill C (2010) Defects in IGF-1 receptor, insulin receptor and IRS-1/2 in Alzheimer's disease indicate possible resistance to IGF-1 and insulin signalling. Neurobiol Aging 31, 224-243.

[33] Arnold SE, Arvanitakis Z, Macauley-Rambach SL, Koenig AM, Wang H-Y, Ahima RS, Craft S, Gandy S, Buettner C, Stoeckel LE, Holtzman DM, Nathan DM (2018) Brain insulin resistance in type 2 diabetes and Alzheimer disease: Concepts and conundrums. Nat Rev Neurol 14, 168-181. 
[34] Schiöth HB, Craft S, Brooks SJ, Frey WH, Benedict C (2012) Brain insulin signaling and Alzheimer's disease: Current evidence and future directions. Mol Neurobiol 46, 4-10.

[35] Jagust WJ, Seab JP, Huesman RH, Valk PE, Mathis CA, Reed BR, Coxson PG, Budinger TF (1991) Diminished glucose transport in Alzheimer's disease: Dynamic PET studies. J Cereb Blood Flow Metab 11, 323-330.

[36] Kellar D, Craft S (2020) Brain insulin resistance in Alzheimer's disease and related disorders: Mechanisms and therapeutic approaches. Lancet Neurol 19, 758-766.

[37] Kastin AJ, Akerstrom V, Pan W (2002) Interactions of glucagon-like peptide-1 (GLP-1) with the blood-brain barrier. J Mol Neurosci 18, 7-14.

[38] Perry T, Lahiri DK, Sambamurti K, Chen D, Mattson MP, Egan JM, Greig NH (2003) Glucagon-like peptide-1 decreases endogenous amyloid-beta peptide (Abeta) levels and protects hippocampal neurons from death induced by Abeta and iron. J Neurosci Res 72, 603-612.

[39] Li L, Zhang Z-F, Holscher C, Gao C, Jiang Y-H, Liu Y-Z (2012) $\left(\mathrm{Val}^{8}\right)$ glucagon-like peptide-1 prevents tau hyperphosphorylation, impairment of spatial learning and ultra-structural cellular damage induced by streptozotocin in rat brains. Eur J Pharmacol 674, 280-286.

[40] Gasparini L, Gouras GK, Wang R, Gross RS, Beal MF, Greengard P, Xu H (2001) Stimulation of beta-amyloid precursor protein trafficking by insulin reduces intraneuronal beta-amyloid and requires mitogen-activated protein kinase signaling. J Neurosci 21, 2561-2570.

[41] Gengler S, McClean PL, McCurtin R, Gault VA, Hölscher C (2012) Val(8)GLP-1 rescues synaptic plasticity and reduces dense core plaques in APP/PS1 mice. Neurobiol Aging 33, 265-276.

[42] Gault VA, Porter WD, Flatt PR, Hölscher C (2010) Actions of exendin-4 therapy on cognitive function and hippocampal synaptic plasticity in mice fed a high-fat diet. Int J Obes 34, 1341-1344.

[43] Hamilton A, Patterson S, Porter D, Gault VA, Holscher C (2011) Novel GLP-1 mimetics developed to treat type 2 diabetes promote progenitor cell proliferation in the brain. J Neurosci Res 89, 481-489.

[44] Lee C-C, Kuo Y-M, Huang C-C, Hsu K-S (2009) Insulin rescues amyloid beta-induced impairment of hippocampal long-term potentiation. Neurobiol Aging 30, 377-387.

[45] Gejl M, Brock B, Egefjord L, Vang K, Rungby J, Gjedde A (2017) Blood-brain glucose transfer in Alzheimer's disease: Effect of GLP-1 analog treatment. Sci Rep 7, 17490.

[46] Femminella GD, Frangou E, Love SB, Busza G, Holmes C, Ritchie C, Lawrence R, McFarlane B, Tadros G, Ridha BH, Bannister C, Walker Z, Archer H, Coulthard E, Underwood BR, Prasanna A, Koranteng P, Karim S, Junaid K, McGuinness B, Nilforooshan R, Macharouthu A, Donaldson A, Thacker S, Russell G, Malik N, Mate V, Knight L, Kshemendran S, Harrison J, Hölscher C, Brooks DJ, Passmore AP, Ballard C, Edison P (2019) Evaluating the effects of the novel GLP-1 analogue liraglutide in Alzheimer's disease: Study protocol for a randomised controlled trial (ELAD study). Trials 20, 191.

[47] Craft S (2012) Intranasal insulin therapy for Alzheimer disease and amnestic mild cognitive impairment: A pilot clinical trial. Arch Neurol 69, 29.

[48] Claxton A, Baker LD, Hanson A, Trittschuh EH, Cholerton B, Morgan A, Callaghan M, Arbuckle M, Behl C, Craft S (2015) Long-acting intranasal insulin detemir improves cognition for adults with mild cognitive impairment or early-stage Alzheimer's disease dementia. J Alzheimers Dis 44, 897-906.

[49] Craft S, Claxton A, Baker LD, Hanson AJ, Cholerton B, Trittschuh EH, Dahl D, Caulder E, Neth B, Montine TJ, Jung Y, Maldjian J, Whitlow C, Friedman S (2017) Effects of regular and long-acting insulin on cognition and Alzheimer's disease biomarkers: A pilot clinical trial. $J$ Alzheimers Dis 57, 1325-1334.

[50] Rosenbloom MH, Barclay TR, Pyle M, Owens BL, Cagan AB, Anderson CP, Frey WH, Hanson LR (2014) A single-dose pilot trial of intranasal rapid-acting insulin in apolipoprotein E4 carriers with mild-moderate Alzheimer's disease. CNS Drugs 28, 1185-1189.

[51] Morris JK, Vidoni ED, Mahnken JD, Montgomery RN, Johnson DK, Thyfault JP, Burns JM (2016) Cognitively impaired elderly exhibit insulin resistance and no memory improvement with infused insulin. Neurobiol Aging 39, 19-24.

[52] Craft S, Raman R, Chow TW, Rafii MS, Sun C-K, Rissman RA, Donohue MC, Brewer JB, Jenkins C, Harless K, Gessert D, Aisen PS (2020) Safety, efficacy, and feasibility of intranasal insulin for the treatment of mild cognitive impairment and Alzheimer disease dementia: A randomized clinical trial. JAMA Neurol 77, 1099-1109.

[53] Hoozemans JJM, Rozemuller AJM, van Haastert ES, Eikelenboom P, van Gool WA (2011) Neuroinflammation in Alzheimer's disease wanes with age. J Neuroinflammation 8, 171.

[54] Stuve O, Weideman RA, McMahan DM, Jacob DA, Little BB (2020) Diclofenac reduces the risk of Alzheimer's disease: A pilot analysis of NSAIDs in two US veteran populations. Ther Adv Neurol Disord 13, 175628642093567.

[55] Daniels MJD, Rivers-Auty J, Schilling T, Spencer NG, Watremez W, Fasolino V, Booth SJ, White CS, Baldwin AG, Freeman S, Wong R, Latta C, Yu S, Jackson J, Fischer N, Koziel V, Pillot T, Bagnall J, Allan SM, Paszek P, Galea J, Harte MK, Eder C, Lawrence CB, Brough D (2016) Fenamate NSAIDs inhibit the NLRP3 inflammasome and protect against Alzheimer's disease in rodent models. Nat Commun 7, 12504.

[56] Côté S, Carmichael P-H, Verreault R, Lindsay J, Lefebvre J, Laurin D (2012) Nonsteroidal anti-inflammatory drug use and the risk of cognitive impairment and Alzheimer's disease. Alzheimers Dement 8, 219-226.

[57] Rivers-Auty J, Mather AE, Peters R, Lawrence CB, Brough D (2020) Anti-inflammatories in Alzheimer's disease-potential therapy or spurious correlate? Brain Commun 2, fcaa109.

[58] Daulatzai MA (2016) Pharmacotherpy and Alzheimer's disease: The M-drugs (melatonin, minocycline, modafinil, and memantine) approach. Curr Pharm Des 22, 24112430 .

[59] Scoriels L, Jones PB, Sahakian BJ (2013) Modafinil effects on cognition and emotion in schizophrenia and its neurochemical modulation in the brain. Neuropharmacology 64, 168-184.

[60] Brandt MD, Ellwardt E, Storch A (2014) Short- and longterm treatment with modafinil differentially affects adult hippocampal neurogenesis. Neuroscience 278, 267-275.

[61] Sahu S, Kauser H, Ray K, Kishore K, Kumar S, Panjwani U (2013) Caffeine and modafinil promote adult neuronal cell proliferation during $48 \mathrm{~h}$ of total sleep deprivation in rat dentate gyrus. Exp Neurol 248, 470-481. 
[62] Murphy HM, Ekstrand D, Tarchick M, Wideman CH (2015) Modafinil as a cognitive enhancer of spatial working memory in rats. Physiol Behav 142, 126-130.

[63] Frakey LL, Salloway S, Buelow M, Malloy P (2012) A randomized, double-blind, placebo-controlled trial of modafinil for the treatment of apathy in individuals with mild-to-moderate Alzheimer's disease. J Clin Psychiatry 73, 796-801.

[64] Forlenza OV, De-Paula VJR, Diniz BSO (2014) Neuroprotective effects of lithium: Implications for the treatment of Alzheimer's disease and related neurodegenerative disorders. ACS Chem Neurosci 5, 443-450.

[65] Wilson EN, Do Carmo S, Iulita MF, Hall H, Ducatenzeiler A, Marks AR, Allard S, Jia DT, Windheim J, Cuello AC (2017) BACE1 inhibition by microdose lithium formulation NP03 rescues memory loss and early stage amyloid neuropathology. Transl Psychiatry 7, e1190.

[66] Kessing LV, Gerds TA, Knudsen NN, Jørgensen LF, Kristiansen SM, Voutchkova D, Ernstsen V, Schullehner J, Hansen B, Andersen PK, Ersbøll AK (2017) Association of lithium in drinking water with the incidence of dementia. JAMA Psychiatry 74, 1005.

[67] Leyhe T, Eschweiler GW, Stransky E, Gasser T, Annas P, Basun H, Laske C (2009) Increase of BDNF serum concentration in lithium treated patients with early Alzheimer's disease. J Alzheimers Dis 16, 649-656.

[68] Forlenza OV, Diniz BS, Radanovic M, Santos FS, Talib LL, Gattaz WF (2011) Disease-modifying properties of long-term lithium treatment for amnestic mild cognitive impairment: Randomised controlled trial. Br J Psychiatry 198, 351-356.

[69] Forlenza OV, Radanovic M, Talib LL, Gattaz WF (2019) Clinical and biological effects of long-term lithium treatment in older adults with amnestic mild cognitive impairment: Randomised clinical trial. Br J Psychiatry 215, 668-674.

[70] Ball MJ (1982) Limbic predilection in Alzheimer dementia: Is reactivated herpesvirus involved? Can J Neurol Sci 9, 303-306.

[71] Itzhaki RF, Cosby SL, Wozniak MA (2008) Herpes simplex virus type 1 and Alzheimer's disease: The autophagy connection. J Neurovirol 14, 1-4.

[72] Lopatko Lindman K, Weidung B, Olsson J, Josefsson M, Kok E, Johansson A, Eriksson S, Hallmans G, Elgh F, Lövheim H (2019) A genetic signature including apolipoprotein $\mathrm{E} \varepsilon 4$ potentiates the risk of herpes simplexassociated Alzheimer's disease. Alzheimers Dement $(N Y)$ 5, 697-704.

[73] Wozniak MA, Mee AP, Itzhaki RF (2009) Herpes simplex virus type 1 DNA is located within Alzheimer's disease amyloid plaques. J Pathol 217, 131-138.

[74] Tzeng N-S, Chung C-H, Lin F-H, Chiang C-P, Yeh C-B, Huang S-Y, Lu R-B, Chang H-A, Kao Y-C, Yeh H-W, Chiang W-S, Chou Y-C, Tsao C-H, Wu Y-F, Chien WC (2018) Anti-herpetic medications and reduced risk of dementia in patients with herpes simplex virus infectionsa nationwide, population-based cohort study in Taiwan. Neurotherapeutics 15, 417-429.

[75] Itzhaki RF, Lathe R, Balin BJ, Ball MJ, Bearer EL, Braak H, Bullido MJ, Carter C, Clerici M, Cosby SL, Del Tredici K, Field H, Fulop T, Grassi C, Griffin WST, Haas J, Hudson AP, Kamer AR, Kell DB, Licastro F, Letenneur L, Lövheim H, Mancuso R, Miklossy J, Otth C, Palamara AT, Perry G, Preston C, Pretorius E, Strandberg T, Tabet N, Taylor-Robinson SD, Whittum-Hudson JA
(2016) Microbes and Alzheimer's disease. J Alzheimers Dis 51, 979-984.

[76] Song X, Xu A, Pan W, Wallin B, Kivlin R, Lu S, Cao C, Bi Z, Wan Y (2008) Minocycline protects melanocytes against $\mathrm{H} 2 \mathrm{O} 2$-induced cell death via JNK and $\mathrm{p} 38$ MAPK pathways. Int J Mol Med 22, 9-16.

[77] Garrido-Mesa N, Zarzuelo A, Gálvez J (2013) Minocycline: Far beyond an antibiotic. Br J Pharmacol 169, 337-352.

[78] Zhu X, Raina AK, Rottkamp CA, Aliev G, Perry G, Boux $\mathrm{H}$, Smith MA (2001) Activation and redistribution of c-jun $\mathrm{N}$-terminal kinase/stress activated protein kinase in degenerating neurons in Alzheimer's disease. J Neurochem 76, 435-441.

[79] Centeno C, Repici M, Chatton J-Y, Riederer BM, Bonny C, Nicod P, Price M, Clarke PGH, Papa S, Franzoso G, Borsello T (2007) Role of the JNK pathway in NMDAmediated excitotoxicity of cortical neurons. Cell Death Differ 14, 240-253.

[80] Forloni G, Colombo L, Girola L, Tagliavini F, Salmona M (2001) Anti-amyloidogenic activity of tetracyclines: Studies in vitro. FEBS Lett 487, 404-407.

[81] Cai Z, Zhao Y, Yao S, Bin Zhao B (2011) Increases in $\beta$-amyloid protein in the hippocampus caused by diabetic metabolic disorder are blocked by minocycline through inhibition of NF- $\kappa$ B pathway activation. Pharmacol Rep 63, 381-391.

[82] Parachikova A, Vasilevko V, Cribbs DH, LaFerla FM, Green KN (2010) Reductions in amyloid-beta-derived neuroinflammation, with minocycline, restore cognition but do not significantly affect tau hyperphosphorylation. $J$ Alzheimers Dis 21, 527-542.

[83] Fan R, Xu F, Previti ML, Davis J, Grande AM, Robinson JK, Van Nostrand WE (2007) Minocycline reduces microglial activation and improves behavioral deficits in a transgenic model of cerebral microvascular amyloid. $J$ Neurosci 27, 3057-3063.

[84] Howard R, Zubko O, Gray R, Bradley R, Harper E, Kelly L, Pank L, O'Brien J, Fox C, Tabet N, Livingston G, Bentham P, McShane R, Burns A, Ritchie C, Reeves S, Lovestone S, Ballard C, Noble W, Wilcock G, Nilforooshan R (2020) Minocycline $200 \mathrm{mg}$ or $400 \mathrm{mg}$ versus placebo for mild Alzheimer's disease: The MADE Phase II, three-arm RCT, NIHR Journals Library, Southampton (UK).

[85] Abuznait AH, Cain C, Ingram D, Burk D, Kaddoumi A (2011) Up-regulation of P-glycoprotein reduces intracellular accumulation of beta amyloid: Investigation of P-glycoprotein as a novel therapeutic target for Alzheimer's disease. J Pharm Pharmacol 63, 1111-1118.

[86] Yulug B, Hanoglu L, Ozansoy M, Isık D, Kilic U, Kilic E, Schabitz WR (2018) Therapeutic role of rifampicin in Alzheimer's disease: Rifampicin in Alzheimer's disease. Psychiatry Clin Neurosci 72, 152-159.

[87] Loeb MB, Molloy DW, Smieja M, Standish T, Goldsmith CH, Mahony J, Smith S, Borrie M, Decoteau E, Davidson W, McDougall A, Gnarpe J, O’Donnell M, Chernesky M (2004) A randomized, controlled trial of doxycycline and rifampin for patients with Alzheimer's disease. $J \mathrm{Am}$ Geriatr Soc 52, 381-387.

[88] Molloy DW, Standish TI, Zhou Q, Guyatt G, DARAD Study Group (2013) A multicenter, blinded, randomized, factorial controlled trial of doxycycline and rifampin for treatment of Alzheimer's disease: The DARAD trial. Int $J$ Geriatr Psychiatry 28, 463-470. 
[89] Hill SM, Cheng C, Yuan L, Mao L, Jockers R, Dauchy B, Blask DE (2013) Age-related decline in melatonin and its MT1 receptor are associated with decreased sensitivity to melatonin and enhanced mammary tumor growth. Curr Aging Sci 6, 125-133.

[90] Poeggeler B, Miravalle L, Zagorski MG, Wisniewski T, Chyan YJ, Zhang Y, Shao H, Bryant-Thomas T, Vidal R, Frangione B, Ghiso J, Pappolla MA (2001) Melatonin reverses the profibrillogenic activity of apolipoprotein E4 on the Alzheimer amyloid Abeta peptide. Biochemistry 40, 14995-15001.

[91] Lahiri DK (1999) Melatonin affects the metabolism of the beta-amyloid precursor protein in different cell types. $J$ Pineal Res 26, 137-146.

[92] Lau WWI, Ng JKY, Lee MMK, Chan ASL, Wong YH (2012) Interleukin-6 autocrine signaling mediates melatonin MT(1/2) receptor-induced STAT3 $\operatorname{Tyr}(705)$ phosphorylation. J Pineal Res 52, 477-489.

[93] Zatta P, Tognon G, Carampin P (2003) Melatonin prevents free radical formation due to the interaction between betaamyloid peptides and metal ions [Al(III), $\mathrm{Zn}(\mathrm{II}), \mathrm{Cu}(\mathrm{II})$, $\mathrm{Mn}(\mathrm{II}), \mathrm{Fe}(\mathrm{II})]$. J Pineal Res 35, 98-103.

[94] Feng Z, Zhang J-T (2004) Protective effect of melatonin on beta-amyloid-induced apoptosis in rat astroglioma C6 cells and its mechanism. Free Radic Biol Med 37, 17901801.

[95] Li X-C, Wang Z-F, Zhang J-X, Wang Q, Wang J-Z (2005) Effect of melatonin on calyculin A-induced tau hyperphosphorylation. Eur J Pharmacol 510, 25-30.

[96] Matsubara E, Bryant-Thomas T, Pacheco Quinto J, Henry TL, Poeggeler B, Herbert D, Cruz-Sanchez F, Chyan Y-J, Smith MA, Perry G, Shoji M, Abe K, Leone A, Grundke-Ikbal I, Wilson GL, Ghiso J, Williams C, Refolo LM, Pappolla MA, Chain DG, Neria E (2003) Melatonin increases survival and inhibits oxidative and amyloid pathology in a transgenic model of Alzheimer's disease. $J$ Neurochem 85, 1101-1108.

[97] Lahiri DK, Chen D, Ge Y-W, Bondy SC, Sharman EH (2004) Dietary supplementation with melatonin reduces levels of amyloid beta-peptides in the murine cerebral cortex. J Pineal Res 36, 224-231.

[98] Ali T, Badshah H, Kim TH, Kim MO (2015) Melatonin attenuates D-galactose-induced memory impairment, neuroinflammation and neurodegeneration via RAGE/NF$\mathrm{K} \mathrm{B} / \mathrm{JNK}$ signaling pathway in aging mouse model. $J$ Pineal Res 58, 71-85.

[99] Rosales-Corral S, Tan D-X, Reiter RJ, Valdivia-Velázquez M, Martínez-Barboza G, Acosta-Martínez JP, Ortiz GG (2003) Orally administered melatonin reduces oxidative stress and proinflammatory cytokines induced by amyloidbeta peptide in rat brain: A comparative, in vivo study versus vitamin C and E. J Pineal Res 35, 80-84.

[100] Zhu LQ, Wang SH, Ling ZQ, Wang DL, Wang J-Z (2004) Effect of inhibiting melatonin biosynthesis on spatial memory retention and tau phosphorylation in rat. J Pineal Res 37, 71-77.

[101] Quinn J, Kulhanek D, Nowlin J, Jones R, Praticò D, Rokach J, Stackman R (2005) Chronic melatonin therapy fails to alter amyloid burden or oxidative damage in old Tg2576 mice: Implications for clinical trials. Brain Res 1037, 209-213.

[102] Jean-Louis G, von Gizycki H, Zizi F (1998) Melatonin effects on sleep, mood, and cognition in elderly with mild cognitive impairment. J Pineal Res 25, 177-183.

[103] Brusco LI, Fainstein I, Márquez M, Cardinali DP (1999) Effect of melatonin in selected populations of sleepdisturbed patients. Biol Signals Recept 8, 126-131.

[104] Furio AM, Brusco LI, Cardinali DP (2007) Possible therapeutic value of melatonin in mild cognitive impairment: A retrospective study. J Pineal Res $\mathbf{4 3}$, 404-409.

[105] Cardinali DP, Furio AM, Brusco LI (2010) Clinical aspects of melatonin intervention in Alzheimer's disease progression. Curr Neuropharmacol 8, 218-227.

[106] Corbett A, Williams G, Ballard C (2015) Drug repositioning in Alzheimer's disease. Front Biosci (Schol Ed) 7, 184-188.

[107] Dubois B, Gauthier S, Cummings J (2013) The utility of the new research diagnostic criteria for Alzheimer's disease. Int Psychogeriatr 25, 175-177.

[108] Daulatzai MA (2015) "Boomerang neuropathology" of late-onset Alzheimer's disease is shrouded in harmful "BDDS": Breathing, diet, drinking, and sleep during aging. Neurotox Res 28, 55-93. 